\title{
Synthesis of Nitrogen and Phosphorus co-doped Carbon with Tunable Hierarchical Porous Structure from Rice Husk for High Performance Supercapacitors
}

\author{
Yuning $Q u^{1}$, Lin Liu ${ }^{1}$, Lisha Li ${ }^{1}$, Shuya Wen ${ }^{2}$,Dan Wei ${ }^{2}$, Ningru Xiao ${ }^{3}$, Feng Yan ${ }^{1}$, \\ Jianguo $\mathrm{Yu}^{1^{*}}$, Lili Wang ${ }^{{ }^{*}}$ \\ ${ }^{1}$ School of Chemistry and Chemical Engineering, Tiangong University, Tianjin 300387, China \\ ${ }^{2}$ School of Enviromental Science and Engineering, Tiangong University, Tianjin 300387, China \\ ${ }^{3}$ School of Physical Science and Technology, Tiangong University, Tianjin 300387, China \\ "E-mail: wanglili@tjpu.edu.cn; hh_y1118@hotmail.com
}

doi: $10.20964 / 2020.03 .43$

Received: 19 October 2019/ Accepted: 11 December 2019 / Published: 10 February 2020

\begin{abstract}
Nitrogen and phosphorus co-doped porous carbon(N/P-PC) was prepared via a simple direct pyrolysis method using rice husks as the carbon source and $\mathrm{H}_{3} \mathrm{PO}_{4}$ as the phosphorus source and activator. The acquired products are typical hierarchical porous carbons with a multiple-peaked pore size distribution of microporous and mesoporous structure, which has a high surface area and pore volume. The $\mathrm{N}_{2}$ adsorption-desorption results show that the mesoporous distribution of N/P-PC can be adjusted in the range of 2-10 nm and the meso-porosity can be varied by changing the $\mathrm{H}_{3} \mathrm{PO}_{4}$ content. In particular, among the N/P-PC samples, N/P-PC-1:5 has the highest surface area of $2188 \mathrm{~m}^{2} / \mathrm{g}$, pore volume of $3.025 \mathrm{~cm}^{3} / \mathrm{g}$, and pore diameter of $5.537 \mathrm{~nm}$. Electrochemical measurements also indicate that the assembled symmetric cell of N/P-PC-1:5 displays the highest specific capacitance of $236 \mathrm{~F} / \mathrm{g}$ at a scan rate of $5 \mathrm{mV} / \mathrm{s}$ and $130 \mathrm{~F} / \mathrm{g}$ at a current density of $0.5 \mathrm{~A} / \mathrm{g}$; it also has an excellent capacity retention of $100 \%$ after 6000 cycles. The hierarchical porous structure and the synergistic action of nitrogen and phosphorus contribute to the advantageous electrochemical performance of the carbon material. The proposed strategy provides a facile method for preparing porous carbon from biomass waste.
\end{abstract}

Keywords: Co-doping, Rice husk, Supercapacitor, Tunable porous

\section{$\underline{\text { FULL TEXT }}$}

(C) 2020 The Authors. Published by ESG (www.electrochemsci.org). This article is an open access article distributed under the terms and conditions of the Creative Commons Attribution license (http://creativecommons.org/licenses/by/4.0/). 